\title{
Modificação do fenótipo periodontal por técnica minimamente invasiva
}

Modification of the periodontal phenotype by minimally invasive technique

Modificación del fenotipo periodontal por técnica mínimamente invasiva

José Henrique de Araújo CRUZ ${ }^{1}$ Itamar da Silva NUNES ${ }^{1}$

Raquel Lira Braga da SILVA ${ }^{1}$

Sarah Cristina de SOUZA $\mathbf{A}^{\mathbf{1}}$

Vinícius Augusto Carneiro PEREIRA ${ }^{1}$

Júlia Tavares PALMEIRA ${ }^{\mathbf{1}}$

Santina Sayanne Leite MINERVINO ${ }^{1}$ Rodrigo Alves RIBEIRO ${ }^{2}$

Rachel de Queiroz Ferreira RODRIGUES ${ }^{2}$ João Nilton Lopes de SOUSA ${ }^{2}$

${ }^{1}$ Cirurgiã(o)-Dentista pelo Curso de Graduação em Odontologia. Centro de Saúde e Tecnologia Rural, Universidade Federal de Campina Grande (UFCG) 58708-110 Patos - PB, Brasil

${ }^{2}$ Professor(a) Doutor(a) da Disciplina de Periodontia do Curso de Graduação em Odontologia. Centro de Saúde e Tecnologia Rural, Universidade Federal de Campina Grande (UFCG) 58708-110 Patos - PB, Brasil

\section{Resumo}

Objetiva-se descrever a modificação do sorriso através da técnica de tunelização com enxerto de tecido conjuntivo no recobrimento radicular de classes I de Miller. Paciente de 24 anos de idade, gênero masculino foi referenciado ao tratamento de recessão gengival constatada no exame clínico e radiográfico no elemento 23, cuja altura de $2 \mathrm{~mm}$, largura de $3 \mathrm{~mm}$ e mucosa queratinizada de $2 \mathrm{~mm}$. Na consulta, optou-se em recobri-la com enxerto de tecido subepitelial tunelizado. Foi realizada anestesia local e incisão intra-sulcular para ser possível descolar a gengiva subsequentemente. Com o tunelizador, preparou-se um túnel muco-periósteo e efetuou-se a terapia mecânica com cureta Gracey 5/6 e química com Ácido cítrico a $10 \%$ por $3 \mathrm{~min}$, para viabilizar a adequação do enxerto. O enxerto de $1,5 \mathrm{~mm}$ de espessura foi retirado do palato em incisão linear, entre a distal do elemento 13 e mesial do elemento 16 , distante $3 \mathrm{~mm}$ da margem gengival. O tecido foi posicionado no local da recessão e mantido por suturas. Confeccionou-se cimento cirúrgico, orientou-se em não higienizar a região e realizar bochecho com Digluconato de Clorexidina 0,12\%. Um planejamento adequado associado a uma excelente técnica de execução e previsibilidade foram ferramentas fundamentais para o sucesso no recobrimento total da recessão e aumento de mucosa queratinizada

Descritores: Periodontia; Retração Gengival; Estética Dentária.

\section{Abstract}

The objective of this study was to describe the smile modulation through the tunneling technique with connective tissue graft in the Miller class I root cover. A 24-year-old male patient was referred to the treatment of gingival recession found in the clinical and radiographic examination in element 23, whose height of $2 \mathrm{~mm}$, width of $3 \mathrm{~mm}$ and keratinized mucosa of $2 \mathrm{~mm}$. In the consultation, it was chosen to cover it with tunnelled subepithelial tissue graft. Local anesthesia and intra-sulcular incision were performed to be able to subsequently remove the gingiva. With the tunelizador, a muco-periosteal tunnel was prepared and mechanical therapy was performed with Gracey 5/6 curette and chemistry with $10 \%$ citric Acid for 3 min, to enable the graft adequacy. The $1.5 \mathrm{~mm}$ thick graft was removed from the palate in a linear incision, between the distal element 13 and mesial element 16, $3 \mathrm{~mm}$ away from the gingival margin. The tissue was positioned at the site of the recession and maintained by sutures. Cement was made surgical, it was advised not to sanitize the region and to perform a mouthwash with $0.11 \%$ Chlorhexidine Digluconate. Adequate planning associated with an excellent execution and predictability technique were fundamental tools for success in the complete coverage of recession and increase of keratinized mucosa.

Descriptors: Periodontics ; Gingival Recession; Esthetics, Dental.

\section{Resumen}

El objetivo es describir la modificación de la sonrisa a través de la técnica de túnel con injerto de tejido conectivo en la cobertura de la raíz de Miller clase I. Un paciente masculino de 24 años fue derivado al tratamiento de recesión gingival que se encontró en el examen clínico y radiográfico en el elemento 23 , cuya altura era de $2 \mathrm{~mm}$, ancho de $3 \mathrm{~mm}$ y mucosa queratinizada de $2 \mathrm{~mm}$. En la consulta, se decidió cubrirlo con un injerto de tejido subepitelial tunelizado. La anestesia local y la incisión intra-sulcular se realizaron para poder separar posteriormente la encía. Con la máquina de tunelización, se preparó un túnel de periostio mucoso y se realizó una terapia mecánica con una cureta Gracey $5 / 6$ y una sustancia química con ácido cítrico al 10\% durante 3 minutos, para hacer factible la adecuación del injerto. El injerto de 1,5 mm de grosor se retiró del paladar en una incisión lineal, entre el elemento distal 13 y el elemento mesial 16, a $3 \mathrm{~mm}$ del margen gingival. El tejido se colocó en el sitio de recesión y se mantuvo mediante suturas. Se hizo cemento quirúrgico, se le ordenó no limpiar la región y enjuagar con digluconato de clorhexidina al 0,12\%. La planificación adecuada asociada con una excelente técnica de ejecución y previsibilidad fueron herramientas fundamentales para el éxito en cubrir toda la recesión y aumentar la mucosa queratinizada. Descriptores: Periodoncia ; Recesión Gingival ; Estética Dental.

INTRODUÇÃO

A recessão gengival é definida por um deslocamento apical da margem gengival, estando frequentemente associada à hipersensibilidade dental e insatisfações estéticas. As recessões gengivais podem ser localizadas, quando afetam apenas um único elemento dentário, ou generalizadas, afetando mais de um dente ${ }^{1}$, além de estarem envolvidas com fatores anatômicos, iatrogênicos e associadas à gengivite e periodontite ${ }^{2}$.
$\mathrm{Na}$ atualidade, observa-se uma procura progressiva por parte dos pacientes em relação às técnicas de cirurgia plástica periodontal, que permitem refinar ou restabelecer a harmonia do sorriso $^{3,4}$. Assim, são procedimentos de cobertura da raiz para corrigir o nível de variação da mucosa queratinizada em torno da superfície dentária causada pela retração gengival ${ }^{5}$.

Há inúmeras técnicas relatadas na 
literatura para o tratamento de recessões gengivais, com diferentes graus de dificuldade e resultados variáveis. Um dos problemas que o clínico encara é especificamente a seleção da técnica mais apropriada para cada caso ${ }^{1,6}$.

A profundidade da recessão, quantidade de gengiva queratinizada apical à recessão e o biótipo gengival são algumas das variáveis que condicionam a seleção da técnica cirúrgica? Além disso, o biótipo gengival varia de individuo para individuo e é uma característica geneticamente determinada, podendo influenciar outras peculiaridades gengivais, como a largura da gengiva ${ }^{8}$.

A técnica de tunelização é uma opção às técnicas convencionais, como a técnica de retalho de reposicionamento coronal com enxerto de tecido conjuntivo (RRC + ETC). Esta técnica de tunelização com ETC (TUN + ETC) tem demonstrado resultados clínicos previsíveis, com efeitos semelhantes ao RRC + ETC, a par de uma excelente integração estética em termos de cor e textura com os tecidos adjacentes ${ }^{9,10}$.

Esta técnica está indicada no tratamento de retrações gengivais de classe I e II de Miller, isoladas ou múltiplas, com profundidade de sondagem menor ou igual a $3 \mathrm{~mm}^{11}$. A ausência de gengiva queratinizada não constitui uma contraindicação, pelo contrário, em virtude do aumento de mucosa queratinizada torna-se indicado $^{12}$. Outrossim, o enxerto deve ficar até 2 $\mathrm{mm}$ exposto $^{13}$, de maneira a aumentar a margem de gengiva queratinizada com 0 transcorrer do processo de cicatrização ${ }^{6}$.

Nesse raciocínio, a técnica de tunelização defende a integridade da papila interdental e a preservação do tecido em questão, buscando tratamento minimamente invasivo $^{14}$. A utilização de instrumentos de microcirurgia permite manusear os tecidos de uma forma mais atraumática ${ }^{15-17}$, rápida revascularização e melhor pós-operatório ${ }^{16,18}$.

Com base no exposto, objetivou-se relatar um caso clínico de recessão gengival sob tratamento minimamente invasivo de enxerto subepitelial.

\section{CASO CLÍNICO}

Paciente de 24 anos de idade, sexo masculino, saudável, não fumante, foi encaminhado à Liga de Periodontia Clínica e Cirúrgica da Universidade Federal de Campina Grande sob queixas de insatisfação estética nos dentes anteriores. Logo após o exame clínico e radiográfico verificou-se retração gengival de Classe I de Miller no elemento dentário $23 \mathrm{com}$ cerca de $2 \mathrm{~mm}$ de altura e $3 \mathrm{~mm}$ de largura (Figura 1). Ainda na primeira consulta, 0 elemento 23 apresentava profundidade de sondagem inferior a $3 \mathrm{~mm}$ e mucosa queratinizada de $2 \mathrm{~mm}$ de altura, tendo preenchido o periograma do respectivo dente e recebido orientação quanto higiene oral para adequação do meio bucal.

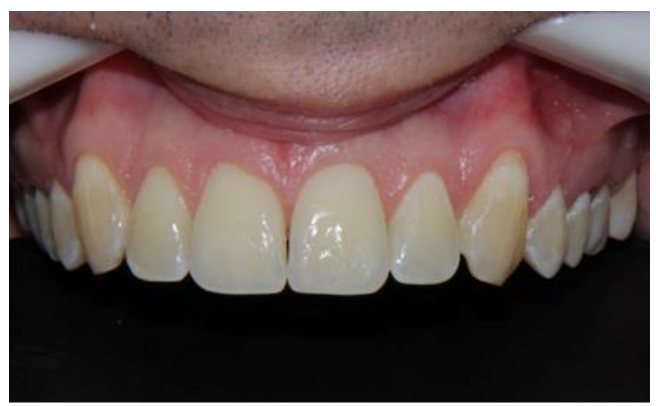

Figura 1: Recessão gengival Classe I de Miller no elemento dental 23 .

Após a adequação do meio oral decidiuse recobrir a recessão gengival através da técnica combinada de Enxerto de Tecido Conjuntivo e Tunelização (ETC + TUN) na região do elemento 23 , com área doadora do palato entre a distal do elemento dental $13 \mathrm{e}$ mesial do elemento dentário 16. Previamente à cirurgia, foi efetuada uma antissepsia perioral com Solução de Clorhexidina a $2 \%$ (Maquire $\AA$, Brasil) e antissepsia intraoral através de bochecho com Solução de Clorhexidina a 0,12\% (Maquire ${ }^{\circledR}$, Brasil) por 1 minuto. Em seguida, realizou-se anestesia com Mepiadre Cloridato de Mepivacaína com Epinefrina (DFL®, Brasil). Com objetivo de preparar o leito receptor do enxerto, o procedimento cirúrgico iniciou através de uma incisão intrasucular na região do elemento 23 com lamina de bisturi no 15 Sterilance (Advantive®), Brasil) (Figura 2).

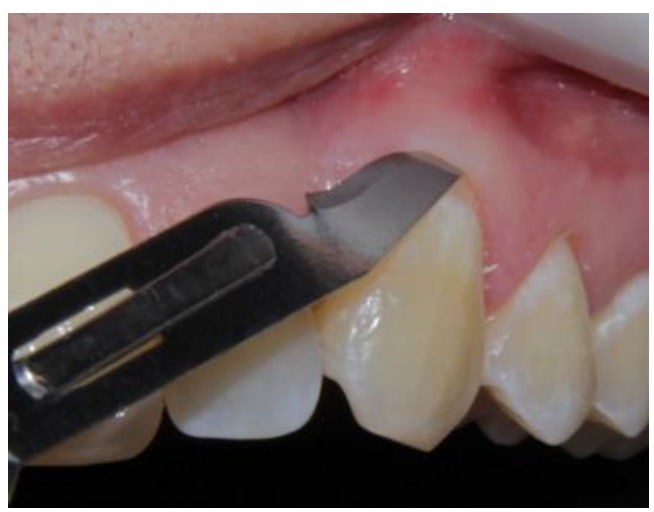

Figura 2: Incisão intrasucular com lâmina de bisturi no 15 preservando as papilas.

Posteriormente, criou-se um túnel supra periósteo com Tunelizador Periodontal até além da linha mucogengival e lateralmente um dente além do elemento 23 , sem envolver papilas gengivais, mas incluindo sua base para posterior elevação do tecido gengival e deslizamento do enxerto (Figura 3).Para a terapia mecânica e alisamento radicular, utilizou-se a cureta 5/6 de Gracey (Figura 4), com posterior terapia química por 3 minutos 
através do uso de Gel de Ácido Cítrico 1\% produzido por manipulação em empresa farmacêutica (Figura 5) com função de preparar o leito para receber o enxerto de tecido conjuntivo. Com sonda Periodontal Carolina do Norte verificou-se a qualidade do túnel e da terapia mecânica e química efetuada (Figura 6).

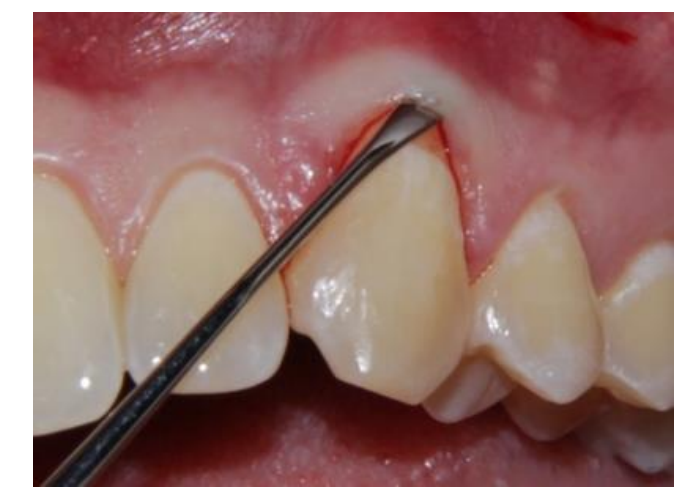

Figura 3: Preparo do túnel com Tunelizador Periodontal.

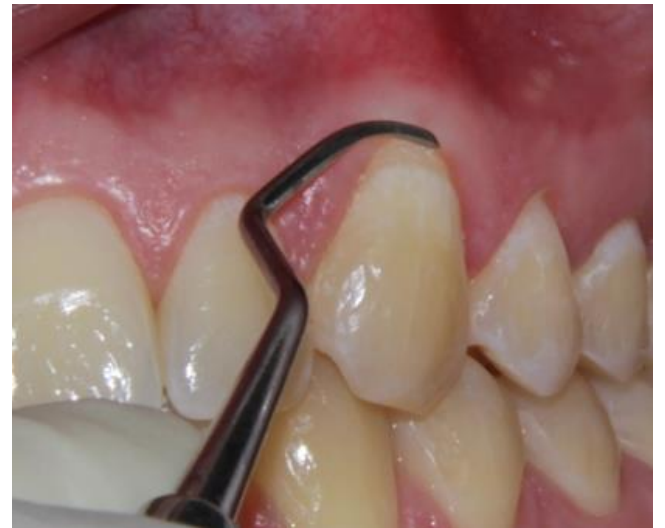

Figura 4: Preparo mecânico com cureta de Gracey 5/6.

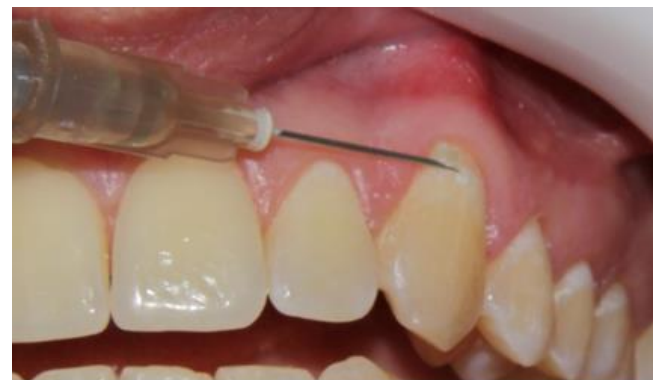

Figura 5: Preparo químico com Ácido Cítrico a 10\% por 3 minutos.

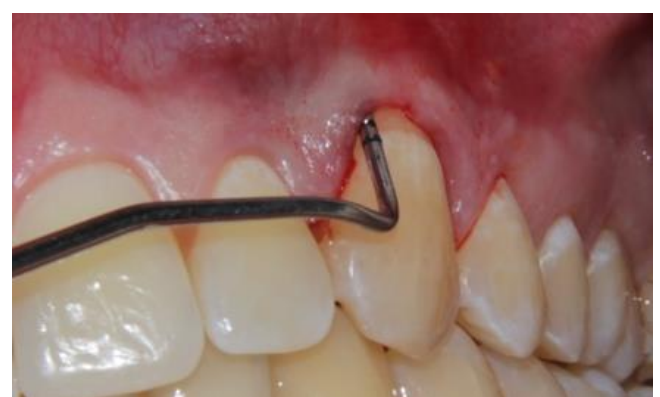

Figura 6: Verificação do Túnel com sonda.

O ETC com $1,5 \mathrm{~mm}$ de espessura foi retirado do palato por meio de uma incisão linear única (Figura 7) na região entre distal do elemento 13 e mesial do elemento 16, distante 3 $\mathrm{mm}$ da margem gengival (Figura 8). A síntese do palato foi executada através de sutura suspensória em " $x$ " (Figura 9) e a do leito receptor do enxerto através de sutura em ponto simples. O enxerto foi levado ao leito receptor e guiado através do túnel por meio de um fio de sutura em Nylon 5-0 Premium Alloy Steel (PolySuture ${ }^{\circledR}$, Brasil) e tunelizador, deixando 1 $\mathrm{mm}$ do enxerto exposto e acima da junção cemento-esmalte (Figura 10).

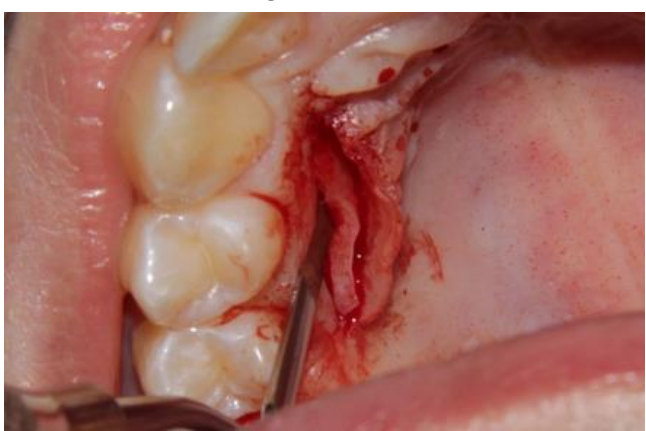

Figura 7: Incisão linear no palato.

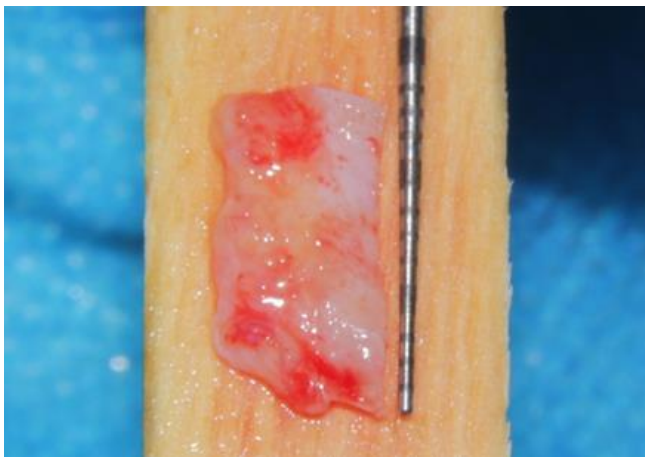

Figura 8: ETC subepitelial.

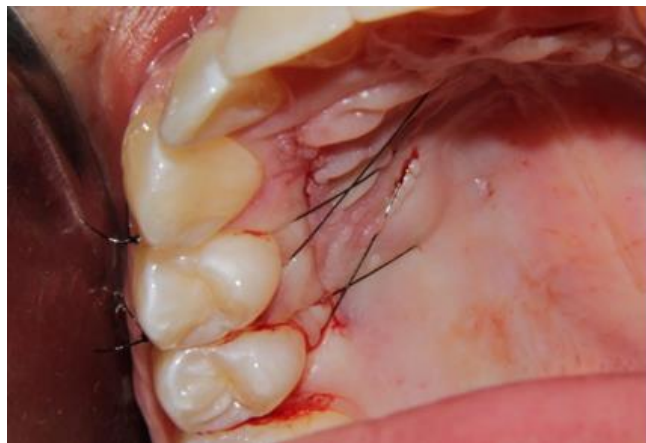

Figura 9: Sutura suspensória em região de palato.

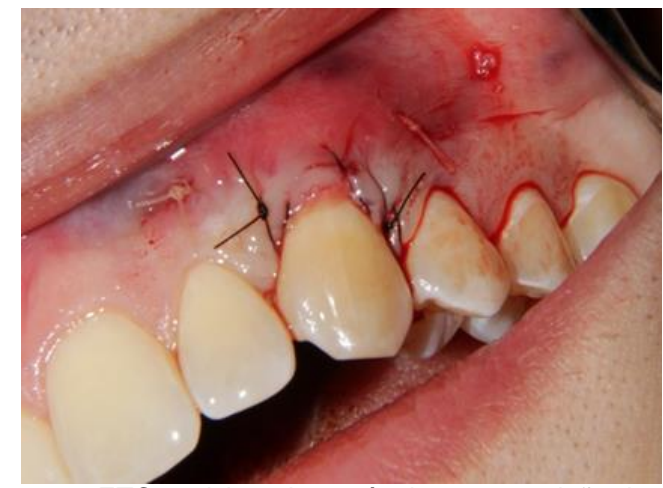

Figura 10: ETC posicionado no túnel com exposição de $1 \mathrm{~mm}$.

Ao término da operação, elaborou-se um curativo com cimento cirúrgico (Perio Bond®, Brasil) e instruiu-se o paciente para privar-se da escovação nas zonas cirúrgicas, não realizar esforço, efetuar bochecho com Solução de 
Gluconato de Clorexidina a 0,12\% (PerioGard $\AA$, Brasil) duas vezes ao dia por 15 dias e foi prescrito Nimesulida $100 \mathrm{mg}$ a cada 12 horas durante três dias e Dipirona 500mg a cada 06 horas durante quatro dias.

Após 12 dias, foi efetuada a remoção do Cimento Cirúrgico da área doadora e da área receptora do enxerto e das respectivas suturas (Figuras 11 e 12), realizado uma antissepsia das zonas com Solução de Gluconato de Clorexidina $0,12 \%$.

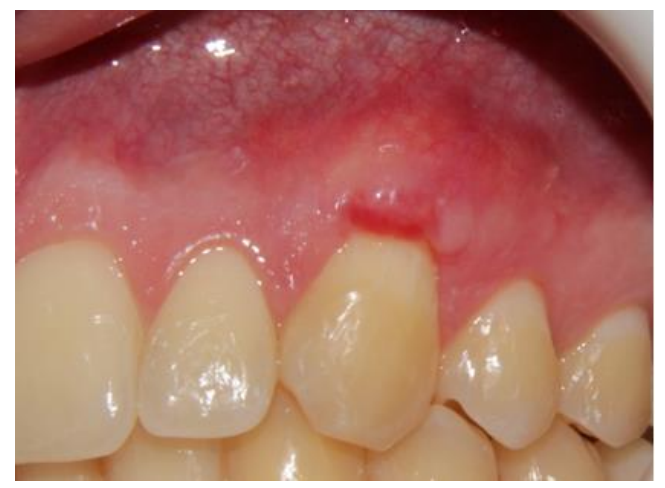

Figura 11: Controle de 12 dias. Aumento de mucosa queratinizada.

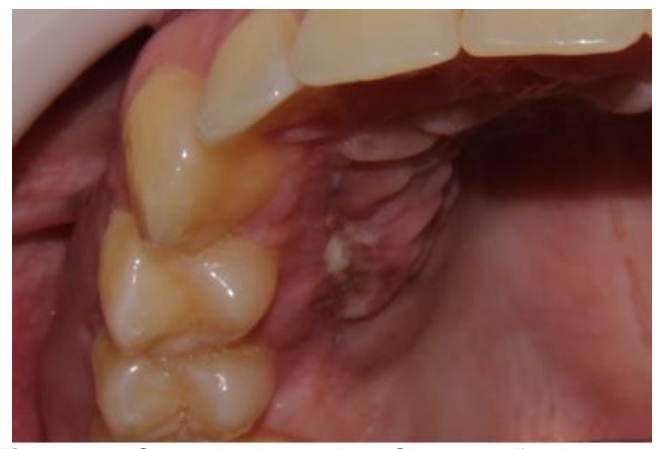

Figura 12: Controle de 12 dias. Cicatrização do palato.

Com 18 dias de pós-operatório, constatou-se a excelente revascularização do enxerto e progressivo aumento de mucosa queratinizada reepitelizando-se (Figuras $13 \mathrm{e}$ 14), conforme as características da mucosa mastigatório encontrada geneticamente no palato, este que encontrava-se em cicatrização evolutiva sem intercorrências.

Aos 32 dias pós-operatórios, observa-se uma extensa área de mucosa queratinizada estendendo-se até a lateral dos elementos dentários vizinhos e com satisfatório recobrimento radicular, além de adequada cicatrização do palato (Figuras 15 e 16).

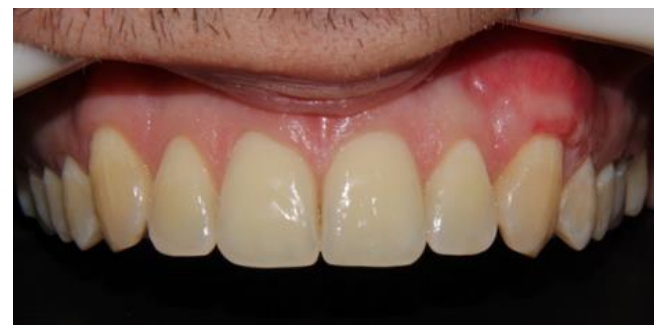

Figura 13: Controle após 18 dias.

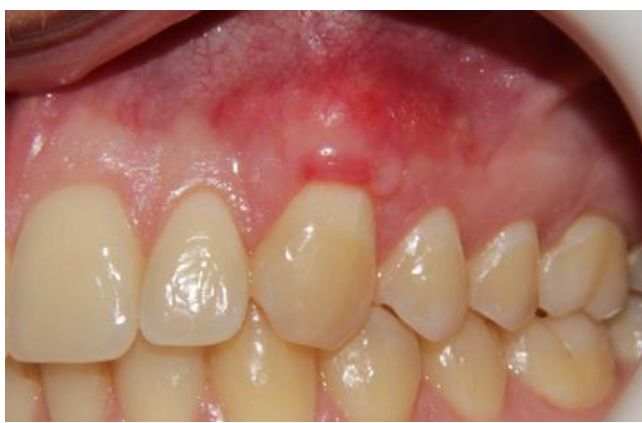

Figura 14: Controle após 18 dias. Área do enxerto exposto revascularizado.

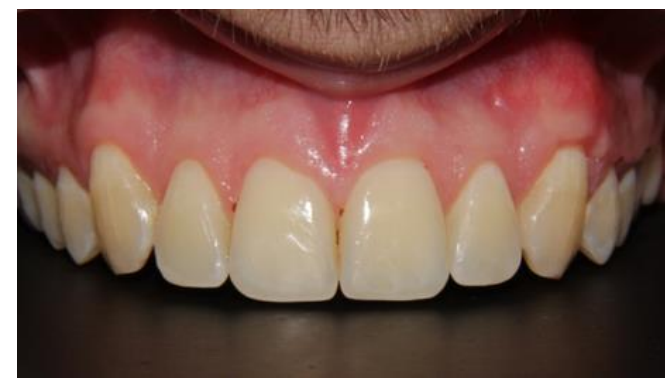

Figura 15: Controle após 32 dias.

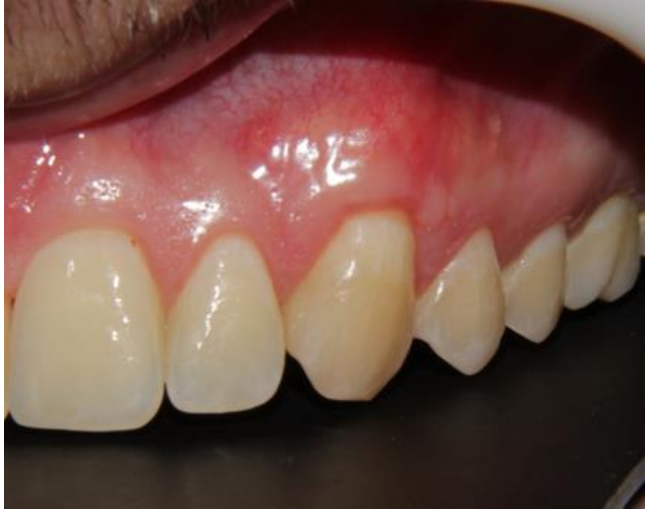

Figura 16: Controle após 32 dias. Vista final.

DISCUSSÃO

A Técnica de Tunelização foi criada como uma alteração da técnica em envelope12, e os resultados segundo a literatura evidenciam prognóstico favorável quanto ao recobrimento radicular e aumento de mucosa queratinizada ${ }^{3,6,9,17,19}$.

Em casos de retrações isoladas ou múltiplas com uma profundidade menor ou igual $3 \mathrm{~mm}$, em que a imposição estética é alta, o procedimento de tunelização poderá ser a opção de escolha, uma vez que permite a preservação das papilas com ausência de incisões de descarga assegurando um melhor suprimento sanguíneo do enxerto e permitindo atingir excelentes resultados estéticos e funcionais a longo prazo $1,9,11,12,17,19$.

O fornecimento de sangue ao enxerto de tecido conjuntivo é o elemento-chave dessa técnica. O uso de um túnel ou um design semelhante a uma bolsa elimina a necessidade de incisões horizontais ou verticais, maximizando assim o papel de fornecimento sanguíneo lateral ao $\mathrm{ETC}^{20}$. 
As porções mais coronais do enxerto podem ficar descobertas a fim de aumentar a banda de gengiva queratinizada. Para prevenir a necrose, é fundamental assegurar que nenhuma porção do enxerto superior a $2 \mathrm{~mm}$ fique exposta, mantendo a maior parte dele coberto pela mucosa do túnel ${ }^{13}$.

A ausência de incisões de descarga, ausência de alterações significativas no posicionamento da linha mucogengival $e$ manutenção da profundidade do vestíbulo são algumas das vantagens desta técnica ${ }^{9}$. Porém, independente das vantagens, compõe uma técnica sensível, que deve ser realizada por um operador experiente com recurso de instrumentos específicos ${ }^{17,18 .}$

Apesar de ser uma técnica sensível, é possível concluir que constitui uma opção de tratamento para recessões classe I e II de Miller ${ }^{6,10,12,13,15}$, assim, confiável para 0 tratamento dessas retrações gengivais, apoiando eficientemente à demanda biológica e estética, estimulando a saúde dos tecidos periodontais e trazendo resultados confiáveis, al em de altamente previsíveis ${ }^{21}$, recuperando forma e função, fisiologia mastigatória, harmonia e estética entre os arcos ${ }^{22}$.

O caso clínico aqui exposto corrobora com a literatura encontrada a respeito da cirurgia plástica periodontal do tipo ETC + TUN, tratamento indicado para retrações gengivais de classe I e II de Miller, uma vez que o paciente relatou rápida recuperação, comprovando os relatos dos estudos já existentes para a técnica, além de satisfação estética após a recuperação total do procedimento.

CONCLUSÃO

Portanto, o planejamento adequado bem como uma excelente técnica de trabalho e habilidade, além de previsibilidade, foram ferramentas essenciais para o sucesso no recobrimento da recessão e aumento de mucosa queratinizada, promovendo estética e conforto ao paciente.

\section{REFERÊNCIAS}

1. Saadoun AP. Current trends in gingival recession coverage--part I: the tunnel connective tissue graft. Pract Proced Aesthet Dent. 2006;18(7):433-8; quiz 440.

2. Baker $P$, Spedding $C$. The aetiology of gingival recession. Dent Update. 2002;29(2):59-62.

3. Rebele SF, Zuhr O, Schneider D, Jung RE, Hürzeler MB. Tunnel technique with connective tissue graft versus coronally advanced flap with enamel matrix derivative for root coverage: a RCT using 3D digital measuring methods. Part II. Volumetric studies on healing dynamics and gingival dimensions. J Clin Periodontol. 2014; 41(6):593-603.

4. Tsourounakis I, Sweidan C, Palaiologou AA, Maney $P$. Coverage of isolated, severe gingival recession: A modified technique. Clin Adv Periodontics; 2014;4:148-53.

5. Rees JS, Addy M. A cross-sectional study of dentine hypersensitivity. J Clin Periodontol. 2002;29(11):997-1003.

6. Ribeiro FS, Zandim DL, Pontes AE, Mantovani RV, Sampaio JE, Marcantonio E. Tunnel technique with a surgical maneuver to increase the graft extension: case report with a 3-year follow-up. J Periodontol. 2008;79(4):753-58.

7. Bouchard P, Malet J, Borghetti A. Decisionmaking in aesthetics: root coverage revisited. Periodontol 2000. 2001;27:97-120.

8. Singh J, Rathod VJ, Rao PR, Patil AA, Langade DG, Singh RK. Correlation of gingival thickness with gingival width, probing depth, and papillary fill in maxillary anterior teeth in students of a dental college in Navi Mumbai. Contemp Clin Dent. 2016;7(4):535-38.

9. Stimmelmayr M, Allen EP, Gernet W, Edelhoff $D$, Beuer $F$, Schlee $M$ et al. Treatment of gingival recession in the anterior mandible using the tunnel technique and a combination epithelialized-subepithelial connective tissue graft-a case series. Int $\mathrm{J}$ Periodontics Restorative Dent. 2011;31(2):165-73.

10.Zuhr O,Rebele SF, Schneider D, Jung RE, Hürzeler MB. Tunnel technique with connective tissue graft versus coronally advanced flap with enamel matrix derivative for root coverage: a RCT using 3D digital measuring methods. Part I. Clinical and patient-centred outcomes. J Clin Periodontol. 2014;41(6):582-92.

11. Miller PD Jr. A classification of marginal tissue recession. Int J Periodontics Restorative Dent. 1985;5(2):8-13.

12. Dani S, Dhage A, Gundannavar G. The pouch and tunnel technique for management of multiple gingival recession defects. J Indian Soc Periodontol. 2014;18(6):776-80.

13. Han JS, John V, Blanchard SB, Kowolik MJ, Eckert GJ. Changes in gingival dimensions following connective tissue grafts for root coverage: comparison of two procedures. $\mathrm{J}$ Periodontol. 2008;79(8):1346-54.

14.Zabalegui I, Sicilia A, Cambra J, Gil J, Sanz M. Treatment of multiple adjacent gingival recessions with the tunnel subepithelial connective tissue graft: a clinical report. Int $\mathrm{J}$ Periodontics Restorative Dent. 1999;19(2): 199-206.

15. Shanelec DA. Periodontal microsurgery. J Esthet Restor Dent. 2003;15(7):402-8.

16. Burkhardt R, Lang NP. Coverage of localized gingival recessions: comparison of micro- and macrosurgical techniques. J Clin Periodontol. 2005;32(3):287-93. 
17. Salama H, Salama M, Garber D. The tunnel technique in the periodontal plastic treatment of multiple adjacent gingival recession defects: $\mathrm{A}$ review. Inside Dentistry. 2008;4:78-81.

18.Zuhr O, Fickl S, Wachtel H, Bolz W, Hürzeler MB. Covering of gingival recessions with a modified microsurgical tunnel technique: case report. Int $\mathrm{J}$ Periodontics Restorative Dent. 2007;27(5):457-63.

19. Allen EP. Subpapillary continuous sling suturing method for soft tissue grafting with the tunneling technique. Int J Periodontics Restorative Dent. 2010;30(5):479-85.

20. Pfeifer JS. The reaction of alveolar bone to flap procedures in man. Periodontics. 1965;3: 135-40.

21.Pazmiño VFC, Rodas MAR, Cáceres CDB, Duarte GGR, Azuaga MVC, de Paula BL et al. Clinical Comparison of the Subepithelial Connective Tissue versus Platelet-Rich Fibrin for the Multiple Gingival Recession Coverage on Anterior Teeth Using the Tunneling Technique. Case Rep Dent. 2017; 2017:4949710.

22. Sa TM, Cruz JHA, Guênes GMT, Almeida MSC, Medeiros LADM, Figueiredo CHMC. A importância da anatomia e escultura dental para prática de procedimentos clínicos odontológicos. Arch Health Invest. 2018;7; (Spec Iss 7):6.

\section{CONFLITO DE INTERESSES}

Os autores declaram não haver conflitos de interesse

\section{AUTOR PARA CORRESPONDÊNCIA}

\section{José Henrique de Araújo Cruz}

Rua Paulo Diogenes, número 57, Centro, 59990 - 000 Rafael Fernandes - RN, Brasil Telefone: (83) 99625-0125.

E-mail: henrique_araujo1992@hotmail.com 